\title{
O ALUNO COM POUCO DOMÍNIO NA LÍNGUA DA \\ ESCOLARIZAÇÃO: CONVERGÊNCIA OU CONCORRÊNCIA DA \\ SOCIALIZAÇÃO LINGUAGEIRA E DA SOCIALIZAÇÃO ESCOLAR?
}

\section{Violaîne Bigot ${ }^{1}$}

Universidade Sorbonne Nouvelle

\section{Resumo}

Este relato etnográfico descreve a participação de S., criança de sete anos de idade e falante não-nativa de língua francesa, nas interações cotidianas em sala de aula. Os dados foram coletados ao longo de cinco meses em classe regular, à qual $\mathrm{S}$. foi integrado, bem como no curso de francês língua estrangeira, por ele frequentado, algumas horas por semana, com outros alunos não-nativos. $\mathrm{O}$ estudo busca mostrar como o desenvolvimento de sua competência comunicativa (ou, mais amplamente, sua socialização em L2) compete com e/ou ajuda, e/ou é ajudado pelo desenvolvimento de outros aprendizagens e por sua socialização escolar.

Palavras-chave: Socialização em L2; Socialização escolar; Aprendizagens escolares; Competência comunicativa em L2; $\quad$ Aquisição em $\quad$ L2.

1 Docente da Universidade Sorbonne Nouvelle - Paris 3. Email: violaine.bigot@univparis3.fr. Texto traduzido por Márcia Romero e Thatiana Ribeiro Vilela. Artigo originalmente publicado sob o título "L'enfant nonfrancophone scolarisé dans une classe ordinaire : convergence ou concurrence de la socialisation langagière et de la socialisation scolaire ?”, in. CANDELIER et al. (eds.): Conscience $d u$ plurilinguisme. Presses Universitaires de Rennes, 2008. Sob o aval da autora, o título do artigo em português foi readequado por sugestão dos tradutores.

Olh@res, Guarulhos, v. 1, n. 2, p. 100-119, Novembro, 2013. 
PUPILS WITH LITTLE MASTERY OF THE LANGUAGE OF SCHOOLING: CONVERGENCE OR CONFLICT BETWEEN LANGUAGE SOCIALIZATION AND SCHOOL SOCIALIZATION

\begin{abstract}
This ethnographic report describes the participation of $\mathrm{S}$, a seven year old non-native speaker child, in the daily classroom interactions of his class. Data were collected over five months. in the "ordinary" classroom where he was integrated as well as in the "special needs" course he attends a few hours a week with other non-native pupils. The study aims at showing how the development of his communicative competence (or more widely, his "L2 socialization) compete with and/or help, and/or is helped by the development of other learnings and of his scholar socialization.
\end{abstract}

Keywords: L2 socialization; Scholar socialization; Scholar learnings; L2 communicative competence; L2 acquisition. 


\section{Contexto de estudo e questões iniciais}

Muitas pesquisas de tipo etnográfico, fundamentadas, como a nossa, em análises de interações verbais em sala de aula, permitiram, nos últimos anos, avançar na compreensão do desenvolvimento das trocas verbais das quais participam as crianças e os adolescentes “alófonos”2 nos primeiros meses de sua escolarização (ver, particularmente, GAJO e MONDADA 2000, VASSEUR 2003, RIVIERE 2005). Nosso estudo inscreve-se nesta perspectiva, mas se interessa por um modo de integração diferente que tende a se desenvolver e que consiste em escolarizar as crianças, desde a sua chegada na França, em classes "regulares”. Essa forma de escolarização pouco foi estudada por pesquisas etnográficas no contexto francês ${ }^{3}$.

Assim, na academia de Nantes $^{4}$, a maioria das crianças e dos adolescentes, se tiveram uma escolarização normal antes de sua chegada na França, é direcionada para as classes regulares. Eles só têm um apoio linguístico verdadeiramente específico algumas horas por semana, em que trabalham com uma professora especializada. Com este acolhimento, a integração escolar da criança parece privilegiada: o que lhe é solicitado é, antes, que aprenda o seu "papel de estudante" no sistema educativo francês, que construa as mesmas aprendizagens que as crianças francesas, postulando-se que "a intendência linguística” 5 acontecerá normalmente. O estudo de caso

\footnotetext{
${ }^{2}$ Nota dos Trad. Pessoa cuja língua materna é diferente daquela da comunidade em que vive.

${ }^{3}$ Alguns estudos foram realizados fora do contexto francês. Podemos citar particularmente o estudo de WELLET (1995), que trata de uma sala mista (5 alunos alófonos em uma sala com 22 alunos) em uma escola internacional de um campus universitário norte-americano e o estudo de PALLOTTI (2005) sobre a socialização linguageira de uma aluna marroquina em uma escola italiana de educação infantil.

4 Nota dos Trad. Na França, a academia constitui uma divisão territorial e administrativa da Universidade, que agrega um conjunto de estabelecimentos e de professores de ensino público de todos os níveis. Nantes, por sua vez, é uma cidade francesa.

${ }^{5}$ Nota dos Trad. Expressão que parece se apoiar na fala do general De Gaulle, que teria afirmado, por volta de 1958, L'intendance suivra toujours, querendo dizer que os problemas econômicos e financeiros do Estado terminam sempre por serem resolvidos, por bem ou por mal. No presente contexto, o que se postula é que se espera que os problemas linguísticos sejam resolvidos normalmente.
}

Olh@res, Guarulhos, v. 1, n. 2, p. 100-119, Novembro, 2013. 
O aluno com pouco domínio na língua da escolarização: convergência ou concorrência da socialização linguageira e da socialização escolar?

apresentado a seguir se propõe a examinar este desafio educativo em uma perspectiva sócio-interacionista centrada nos processos de apropriação da linguagem.

No âmbito das diferentes observações, conduzidas em campo na cidade de Angers, em classes de integração e de acolhimento $^{6}$, acompanhei durante cinco meses um garoto albanês, doravante S., chegado na França em outubro de $2005^{7}$. Com idade de seis anos, foi escolarizado desde a sua chegada em uma sala de ciclo 2 de uma área de educação prioritária chamada de "ambição-êxito”. Eu o encontrei, observei e gravei, antes, nos cursos de francês língua estrangeira que ele tinha três vezes por semana com outra aluna, Nora. Depois, entre março e junho de 2006, passei por volta de trinta horas em sua sala (três observações por mês em média) e recolhi por volta de quinze horas de gravações ${ }^{8}$.

Vamos examinar, por meio da análise das trocas verbais das quais $\mathrm{S}$. participa, a maneira como ele se categoriza ou não como bilingue, alófono, aprendiz. Veremos também, por meio desse estudo de caso, que, entre as interações de grandes desafios comunicacionais e certas interações perfeitamente rotinizadas (rituais de datas, etc.), existe toda uma gama de interações que lhe oferecem a ocasião de explorar, às vezes de maneira muito sistemática, diferentes dimensões

\footnotetext{
${ }^{6}$ Nota dos Trad. Uma classe de acolhimento, no original Classe d'accueil (CLA), é um curso de francês como segunda língua oferecido em uma escola da Educação Nacional. Os alunos são conduzidos a esta classe pelo Centro acadêmico para a escolarização das crianças alófonas recém-chegadas (CASNAV) de sua academia.

${ }^{7}$ S. chegou com seus pais e sua irmã menor. Seus pais são não-francófonos no momento de sua chegada na França. Sua mãe fala apenas albanês. Seu pai, pedreiro, especializado na restauração de edifícios, fala também macedônio, língua de sua cidade. A família mora em um centro de solicitantes de asilo situado próximo da escola. S. segue seus estudos com assiduidade. Ele participa com seus pais das atividades extracurriculares oferecidas às famílias pela escola depois do horário de aula.

${ }^{8}$ De acordo com a professora, reservei momentos de observação participante, em que trabalhava com o grupo de alunos do curso preparatório do qual fazia parte S. enquanto a professora trabalhava com os alunos do curso elementar, primeiro ano. Eu era muito solicitada pelos alunos, que quase não me deixavam disponível para "observar". Esses momentos tinham, entre outros objetivos, o de permitir a médio prazo que minha presença fosse aceita pelas crianças para que eu pertubassse o menos possível a sala durante o tempo de observação não-participante. Que todos os adultos e crianças que aceitaram e facilitaram a minha presença na sala sejam aqui agradecidos. Agradeço também a Jo Arditty, que, mais uma vez, me incentivou e apoiou com sua leitura de uma primeira versão deste artigo.
}

Olh@res, Guarulhos, v. 1, n. 2, p. 100-119, Novembro, 2013. 
de sua competência linguística, diferentes micro-sistemas de sua interlíngua.

\section{Uma identidade plurilíngue mantida à distância}

\subsection{Centração do professor nas tarefas de aprendizagem}

Nas sequências de aprendizagem dessa classe regular, as focalizações metalinguísticas são pouco numerosas e mesmo quando, de nosso ponto de vista de observadora e familiarizada com aulas de língua, nos parecia evidente que a incapacidade de S. em realizar uma atividade estava ligada a um problema de compreensão do que lhe era solicitado, as trocas verbais não apresentavam as características de bifocalização descritas por BANGE (1992).

Para ilustrar nosso propósito com um exemplo que é deveras numeroso no corpus, podemos evocar a seguinte interação. A professora (doravante P.) pediu aos alunos que escrevessem palavras começando com a sílaba "sa” e S. propôs “maison” [casa]. Quando, logo depois, P. solicita uma palavra iniciada por “re”, S. propôs "savon” [sabão], que é o exemplo que foi considerado e escrito no quadro para a sílaba “sa”. Então P. lhe pergunta "Em SAvon, eu ouço“re”?”. Uma aluna propõe “robe” [vestido]. A reposta é comentada e novamente a professora questiona S. ("Então, S. encontrou?”). Este, mais uma vez, propõe “savon” [sabão] e a professora lhe pergunta de novo: "Então, S., eu ouço "re" em “savon”?”. Ora, a professora concordou, quando falamos do ocorrido, em admitir que S., que fazia parte dos alunos de $\mathrm{CP}^{9}$ que tinham compreendido globalmente a atividade, tinha provavelmente encontrado um problema de compreensão do que lhe foi solicitado. $\mathrm{Na}$ sala, no entanto, ela reagia como faria com qualquer aluno francófono,

\footnotetext{
${ }^{9}$ Nota dos Trad. CP de curso preparatório, primeiro ano de ensino da escola básica francesa.

Olh@res, Guarulhos, v. 1, n. 2, p. 100-119, Novembro, 2013.
} 
tentando fazer com que S comparasse a tarefa realizada com a que foi prescrita, sem chamar a atenção para o discurso de prescrição.

Os exemplos de mal-entendidos desse tipo, que não dão lugar às sequências metalinguísticas, são numerosos e, desse ponto de vista, a interação didática à qual é exposto $\mathrm{S}$. diverge da que podemos observar em classes "restritas" de tipo CLIN ou CLA ${ }^{10}$ (cf. particularmente os trabalhos de RIVIERE sobre as instruções verbais dadas em classe de acolhimento). Poderíamos ver, nessas trocas verbais, o fato de se ter perdido a ocasião de se trabalhar, em contexto, verbos frequentes como “commencer par” [começar por] ou “entendre” [ouvir], mas este não é o nosso objetivo. Com efeito, é necessário constatar:

1. que S., apesar dos frequentes mal-entendidos que barram a compreensão do que lhe é solicitado, constrói, no mesmo ritmo que seus colegas de sala, aprendizagens matemáticas e de leitura-escrita. Como veremos abaixo, perguntamo-nos sobre a existência de outros lugares interacionais, na vida da classe, favoráveis a um trabalho metalinguístico;

2. a atitude da professora aparece no momento em que S., de um lado, recusa ser categorizado nas trocas verbais como locutor nãoexperiente ou simplesmente plurilíngue e, de outro, mobiliza seus recursos linguísticos para poder participar, como os outros alunos, das trocas que fundam a vida do grupo na sala, como veremos adiante.

\subsection{Recusa de S de ser categorizado como locutor não-experiente}

Se a professora, nas atividades de aprendizagem, não tematiza os problemas linguísticos que S. pode encontrar, ela o faz, entretanto, seja nas atividades nas quais o vocabulário está no coração da aprendizagem (ficha de palavras cruzadas temáticas ou descoberta de um novo texto no livro de leitura, por exemplo), seja, quase

\footnotetext{
${ }^{10}$ Nota dos Trad. CLIN são classes de iniciação para alunos não-francófonos que acabaram de chegar na França, assim como as CLA, classes de acolhimento já explicadas acima.

Olh@res, Guarulhos, v. 1, n. 2, p. 100-119, Novembro, 2013.
} 
sistematicamente, na atividade ritual de leitura, pela manhã, do cardápio. Encontramos, então, uma ou mais questões direcionadas a S. sobre sua compreensão do vocabulário. Este nunca se engaja naturalmente nessas trocas verbais que o categorizam como locutor pouco experiente. Ele procura evitar ou encurtar as sequências de explicação de vocabulário que lhe são direcionadas. Frequentemente, responde que compreendeu desde a primeira pergunta da professora. Às vezes, quando a pergunta é muito insistente ou precisa, ele admite que não compreendeu, mas, qualquer que seja a explicação que lhe é dada, ele pretende ter compreendido ${ }^{11}$. Pode-se evocar, assim, essa interação surpreendente em que a professora, depois de ter explicado o que é o trigo, pergunta para S se ele entendeu. S. concorda e quando a professora, para verificar, the pergunta de que cor é o trigo, ele responde rapidamente "rouge” [vermelho]. Esta atitude, que a própria professora comentou durante nossas conversas, pode ser colocada em paralelo com a recusa de S. de ser categorizado como locutor plurilíngue.

\subsection{Recusa de S de ser categorizado como locutor bilíngue}

Por duas vezes, durante minhas observações, S. mostrou bem pouca boa vontade quando suas competências como plurilíngue foram solicitadas. A professora, ao retomar o canto do galo nas diferentes línguas européias, perguntou para S. como era na Albânia. S não manifestou nenhum entusiasmo em responder a pergunta, que pareceu não compreender (o que era surpreendente, dado o contexto). Com a insistência da professora, acabou dizendo, sem nenhum entusiasmo, o termo albanês que designa o galo. Do mesmo modo, na ocasião de um aniversário, “Happy birthday to you” foi cantado pelos alunos em três

\footnotetext{
${ }^{11}$ Notamos, no entanto, que ele sabe muito bem tirar proveito de seu estatuto de alófono nas interações de jogos evidenciadas na parte 3 , em que trapaceia "tranquilamente", contando com a clemência de seus colegas, ou, simplesmente, "não escutando" as observações que alguns alunos, um pouco menos "tolerantes", lhe fazem sobre as regras a serem seguidas. Temos um exemplo de estratégia de malentendido cuidadosamente preservado no final da segunda passagem, em que S literalmente não escuta a pergunta de Amal.
}

Olh@res, Guarulhos, v. 1, n. 2, p. 100-119, Novembro, 2013. 
línguas diferentes. Uma aluna de origem turca cantou em sua língua materna. S., que em um outro momento das gravações canta sozinho uma canção em francês que aprendeu na sala, não responde à solicitação para que cante em albanês e aprova quando a professora conclui: “isso não existe em albanês”.

Pode-se fazer a hipótese de que, para S., a falta de competência em francês está diretamente relacionada à sua competência em albanês (não sei falar francês porque sou albanófono) e que isso explica sua recusa não apenas de ser categorizado como locutor não experiente em francês, mas também como locutor experiente em outras línguas, mesmo se esta categorização possa ser sentida, por outras crianças que não têm a mesma insegurança em francês, como valorizante.

\subsection{Identidade de um aluno regularmente reafirmada}

S., em compensação, participa com muito boa vontade de muitas atividades que contribuem para lhe conferir um estatuto idêntico ao de seus colegas de sala. Nas aulas de matemática ou de francês, participa ativamente e a professora deve lembrá-lo de "levantar o dedo". Ele responde às vezes de maneira fantasiosa, o que dá a impressão de que ele mais quis participar do que responder ao que foi solicitado. Participa regularmente das trocas verbais que acontecem a cada volta da recreação, em que os alunos podem falar das discussões e briguinhas que tiveram com seus colegas. Durante essas trocas, mesmo se não foi diretamente mencionado, S. está sempre bastante atento. Ele se defende se percebe que falam dele, se desculpa quando a professora lhe pede para fazê-lo, mas também toma espontaneamente a palavra, como nessa interação de 23 de março, em que, assim que voltaram para sala, S. e um outro de seus colegas levantaram a mão, antes mesmo que todos os colegas estivessem sentados:

Olh@res, Guarulhos, v. 1, n. 2, p. 100-119, Novembro, 2013. 


\section{Recorte 1: Retorno do recreio - 23 de março ${ }^{12}$}

1. P.: S., você tinha algo a dizer?

2. S.: Bachir, ele disse bebê (para ?) mim.

3. Alunos: <risadinhas>

4. P.: Não... Mas... não estou vendo graça nisso, porque isso não tem graça pra $\mathrm{S}$.

5. Bachir: Eu não lhe disse isso, eu disse pra mim mesmo

6. P.: Peça desculpas, porque aparentemente S. pensou que era pra ele. Então, você explica pra ele.

7. Bachir: Você pode me desculpar?

8. P.: Você tá vendo! Aparentemente, ele tá zangado. Explica o que aconteceu.

9. Bachir: Não disse isso pra você.

10. P.: S., Ouviu o que ele disse?

11. Bachir: Não disse pra você, $S$.

12. S.: Se ele disse mim (aqui/se?) Bachir disse mim.

A atitude extremamente atenta de S. (e, em geral, de toda a sala) durante essas interações mostra que ele compreendeu o que estava em jogo em termos do cotidiano da classe. Segundo o que foi contado por duas professoras, S. foi frequentemente atacado desde o início das aulas, pois tinha, nos primeiros meses, um comportamento considerado agressivo por seus colegas. No momento em que começamos nossas observações, não somente as queixas estavam menos frequentes, mas também vimos vários colegas defendê-lo espontaneamente quando Bachir, na semana seguinte, acusou S. de ter lhe dado uma bofetada.

\footnotetext{
${ }^{12}$ CONVENÇÕES DE TRANSCRIÇÃO

$<$ em voz baixa $>$ entre $<>$ : descrição de elementos paraverbais ou não-verbais.JOGOSAs maiúsculas indicam que uma ou mais sílabas foram evidenciadas por um acento de intensidade.+pausa $(++/+++$ pausas mais longas). Acima de 5', a duração é indicada entre parênteses $\square$ A curva entonativa do grupo rítmico é globalmente ascendente.ma :A sílaba é alongadaXXXSequência inaudível, o número de X correspondente aproximadamente ao número de sílabasXX (Você vem ?)Sequência reconstituída e da qual o transcritor não tem certeza. A : assim eu. A : é isso. As palavras assinaladas indicam a parte dos enunciados que se encavalam $P$ desde sempre $=A$ =SIMA encadeia imediatamente, sem a menor pausa, sobre a fala de P.[gest]Transcrição fonética
}

Olh@res, Guarulhos, v. 1, n. 2, p. 100-119, Novembro, 2013. 


\subsection{A emergência de uma consciência de aprendizagem e a entrada na comunidade dos locutores francófonos}

A recusa de ver seu plurilinguismo tematizado nas interações da sala pode ser esclarecida pelas interações que aconteceram fora da sala de aula e em que S. teve oportunidade de falar ou não de sua relação com as línguas e a aprendizagem. Durante a conversa que organizamos com seus professores e uma intérprete para explicar aos pais de S. o sentido das observações que tínhamos começado e solicitar-lhes a autorização para gravação, eu tinha, ingenuamente, perguntado para S. se ele tinha a impressão de ter feito progressos desde a sua chegada na França. Como ele não respondia, o intérprete traduziu e S., sempre mudo, apertou sua mãe com um sorriso incomodado. Minha pergunta visivelmente não fazia sentido para ele.

No início do mês de junho, dois alunos armênios, principiantes, chegaram na escola. As aulas para os alunos alófonos foram reorganizadas. Nora, mais velha, originária de um país da África francófona e escolarizada na França, naquele momento, há mais de dezoito meses, deixou o curso e S. se encontrou na posição de "locutor experiente” com relação a seus dois novos colegas. A professora encarregada desses cursos de francês como segunda língua me contou que, no início da primeira aula com os dois alunos armênios, S. sussurrou em seus ouvidos, com um grande sorriso: "Eles são como eu”, depois, ao final da aula "Eles não sabem falar francês". Assisti à segunda aula com os dois alunos armênios. Quando soava a sirene de um caminhão de bombeiro, a professora aproveitou o momento para introduzir e/ou lembrar um pouco de vocabulário. S. começou a contar uma intervenção de bombeiro que ele tinha visto no dia anterior. A complexidade e a duração da sua história constrastavam fortemente com as intervenções rápidas que eu tinha ouvido até aquele momento. S. excluiu, assim, as duas crianças armênias da interação para formar, momentaneamente, uma 
comunidade de interlocutores francófonos com sua professora e comigo.

O que nos revelam os discursos (e os silêncios) de S. é que, único aluno não francófono na escola até a chegada dos dois alunos armênios, ele tinha dificuldades para construir uma "escala" que lhe permitisse mensurar a evolução de sua competência linguística. A chegada das duas crianças não-francófonas torna palpáveis para S. os níveis inferiores ao que, naquele momento, tinha atingido em sua competência com relação ao francês. Esse acontecimento resgata, provavelmente, o estado de isolamento linguístico do qual saiu. Pelos dois comentários que fez sobre seus colegas récem-chegados e pela conversa que tem com seus dois parceiros francófonos, ele mostra que é capaz, naquele momento, de conciliar sua identidade de não-nativo, de aprendiz e de membro da comunidade francófona. Neste espaço protegido que é o da classe de apoio linguístico, vai poder se categorizar ao mesmo tempo “como eles”, sentindo-se menos isolado em suas dificuldades diante do francês, mas também como um locutor francófono capaz de conduzir uma conversa e de ser compreendido por esses interlocutores nativos.

\section{Um trabalho de apropriação discreto}

Se ele participa ativamente das interações didáticas nas aulas de aprendizagens matemáticas ou de leitura-escrita, é mais frequentemente para responder às questões da professora e suas intervenções se limitam, portanto, a respostas de uma ou duas palavras que aparecem entre a pergunta e a avaliação da professora (cf. estrutura de interação ternária estudada por Sinclair e Coulthard, comentada particularmente em BANGE, 1992). Vimos, no primeiro recorte, um exemplo de tomada de fala mais complexo, durante uma discussão na volta da recreação. Se há de fato estratégia de comunicação da parte de S. para convencer de sua boa fé no turno 12, não há estratégia de aprendizagem (por exemplo, não há retomada do

Olh@res, Guarulhos, v. 1, n. 2, p. 100-119, Novembro, 2013. 
O aluno com pouco domínio na língua da escolarização: convergência ou concorrência da socialização linguageira e da socialização escolar?

dado de Bachir, que, em 11, emprega o verbo “dizer” acompanhado da preposição "para”"13), provavelmente porque o desafio comunicativo é demasiadamente intenso para que S. pudesse dedicar a "atenção particular” necessária para uma estratégia de aprendizagem ser “em parte buscada por si só” e pudesse, assim, ter por resultado “a aquisição” de novos meios de comunicação em L2 (BANGE, 1992, p.64). Entre as interações em que, para fazer seu papel de aluno, S. só precisa participar com algumas palavras isoladas e as interações em que todo o seu ser está implicado, é dada prioridade à busca da meta comunicativa, não deixando espaço para qualquer trabalho metalinguístico. Pode-se perguntar, então, quais são as interações, em um dia de escola, que favorecem o compromisso de S. na exploração e no desenvolvimento de sua competência linguística.

\subsection{Aquém e além da zona de desenvolvimento proximal ${ }^{14}$}

WILLET (1995, p.481) nota, na sala que observou, que depois de algumas semanas, um observador exterior não é mais capaz de distinguir as crianças récem-chegadas das crianças anglófonas porque “se pedia às crianças inglês segunda língua o mesmo que às crianças linguisticamente experientes: elas realizavam as mesmas tarefas, seguiam as mesmas regras e utilizavam o mesmo material”. O mesmo acontece com S. No entanto, por vezes, relaxa completamente sua atenção nas interações que inflamam seus colegas, e isso porque lhe faltam conhecimentos ao mesmo tempor referenciais e linguísticos para acompanhar, nem que seja globalmente, as trocas que se desenvolvem. É assim em interações de preparação para a “aula

\footnotetext{
${ }^{13}$ Nota dos Trad. Em francês, ele não retoma a preposição A, solicitada pelo verbo DIRE. O que a autora aponta é, portanto, que S. não se apropria da estrutura sintática verificada, dizendo "Bachir disse mim" ao invés de "Bachir disse para mim".

${ }^{14}$ Lembremo-nos de que o conceito desenvolvido por VYGOTSKI é definido como o que a criança "sabe fazer hoje em colaboração" e que ele "saberá fazer amanhã sozinho". Esta zona, que "determina as possibilidades de aprendizagem” (VYGOTSKI, 1997, p.355-356), é delimitada por um limite inferior (abaixo do qual se encontra o que a criança sabe fazer sozinha) e um limite superior, para além do qual se encontra o que a criança não pode ainda fazer, mesmo com a ajuda de um adulto.
}

Olh@res, Guarulhos, v. 1, n. 2, p. 100-119, Novembro, 2013. 
verde” 15 ou de preparação de um encontro esportivo inter-escolas. Durante essas interações, S. parece “sonhar”. O contraste é importante com as atividades rituais, das quais, como já dissemos, S. participa ativamente. Ao final do ano escolar, ele está, inclusive, mais atuante do que alguns colegas para o ritual da data, que consiste em dizer, em um formato de frase imposta, a data do dia anterior, a data do dia e a data do dia seguinte. Se a aprendizagem dessas frases provavelmente contribuíram, nos primeiros meses, para o armazenamento de “expressões modelos” que são conhecidas como uma das fases de aquisição em crianças, parece bem que, no final do ano, sua participação entusiasta nestas atividades não tem mais do que uma função socializante.

Entre as interações que estão para além de sua capacidade de linguagem, porque as temáticas desenvolvidas são muito desconectadas do contexto imediato ou dos temas recorrentes da aula e as interações altamente ritualizadas que, ao final do ano letivo, só solicitam de S. intervenções localizadas abaixo de sua zona de desenvolvimento proximal, há toda uma gama de interações que lhe permitem explorar os micro-sistemas de sua interlíngua.

\subsection{As interações de jogo}

Quando eles terminaram uma atividade e a professora está ocupada com alunos de $\mathrm{CE} 1^{16}$, os alunos de CP têm o direito de brincar com jogos de tabuleiro. S. frequentemente toma a iniciativa de propor partidas de xadrez ou de outros jogos do tipo dominó. Essas situações regradas, em que os desafios são imediatos, ao mesmo tempo reais e limitados, constituem um espaço propício às atividades linguageiras de apropriação. Assim, em 20 de junho, quando sua colega come seu peão em uma partida de xadrez dizendo "Eh, bem,

\footnotetext{
${ }^{15}$ Nota dos Trad. A “aula verde” (classe verte) é uma saída escolar durante a qual os alunos partem em descoberta da natureza sem os pais, mas acompanhados pelos professores.

${ }^{16}$ Nota dos Trad. Sigla para Curso Elementar primeiro ano. Vem logo após o CP.

Olh@res, Guarulhos, v. 1, n. 2, p. 100-119, Novembro, 2013.
} 
tchau tchau", ele, por sua vez, come uma peça repetindo o que se apropriou da expressão: "Eh tchau tchau tchau”. Muitas vezes, instalando seus peões brancos (sua cor favorita) para uma partida de xadrez, ele comenta a ausência de um peão que foi substituído, na caixa, por um peão diferente daqueles do jogo, já que de cor preta. Em 30 de março, ele disse colocando o peão no tabuleiro: “não é branco" ${ }^{17}$. Em 01 de junho, ele participou de um jogo de cartas com Amal que tenta, em vão, fazer com que S. baixe, de suas cartas, as que tinham um pequeno logotipo com uma casa vermelha. Ela lhe pergunta se ele tem ainda cartas como essa, lembrando-lhe que ela baixou uma, e enfatiza o fato de que ela mesma não tem mais cartas assim e que ele, certamente, tem outras. S. está disposto a admitir que tem cartas com casas, mas não com “casas vermelhas”.

\section{Recorte 2: Jogo, tempo livre - 01 de junho}

1. A.: eu, eu não tenho mais com esse negocinho vermelho embaixo

2. S.: X

3. A.: $\mathrm{X}$ casa casinhas vermelhas embaixo aqui, você, você tem muitas. Você sabe $\mathrm{X}$ (quantas?) Eu estou vendo aqui. Tem casinhas vermelhas.

4. S.: Aqui tem casinhas vermelhas isso isso isso

5. A.: olhe as casinhas vermelhas

6. S.: Sim, mas eu não tenho vermelha, eu aqui

7. A.: Eu só tenho uma

8. S.: < olha uma a uma suas cartas tranquilamente > mas isso, uh, não é + vermelho + vermelho + isso não é vermelho + isso não é vermelho + isso isso não é vermelho + isso não é vermelho + isso não é vermelho.

Além da repetição no turno 4, que talvez seja a manifestação de algo que foi compreendido, parece interessante nos atermos na série de auto-retomadas na intervenção 8. A auto-reformulação que intervém é muito marcante, pois corresponde a uma modificação para se obter maior conformidade com a norma linguística e não deixa de lembrar o auto-apoio mencionado por Pallotti (2005, p.115). Deve-se notar, porém, que nada na entonação sugere um trabalho de auto-reparação. Nada permite afirmar que o reajustamento em direção à

\footnotetext{
${ }^{17}$ Nota dos Trad. Vale observar que, em francês, o que S. disse foi "est pas blanc", quando deveria ter colocado, no enunciado, o pronome Il diante do verbo (Il est pas blanc).

Olh@res, Guarulhos, v. 1, n. 2, p. 100-119, Novembro, 2013.
} 
norma linguística é fruto de um trabalho consciente, mas esses três recortes, dentre muitos outros que podemos mencionar, atestam uma atividade de linguagem intensa durante os momentos de jogo. Poderíamos aproximar essas sequências de outras passagens de interações bastante lúdicas em que $\mathrm{S}$. parece explorar as zonas instáveis de sua interlíngua.

Em 23 de março, S., organizando-se para a recreação, disse com satisfação "biblioteca minha + + biblioteca". Ele evoca, assim, para si, a pequena biblioteca de 14 livros, denominada assim pela professora, que esta lhe fez fazer ao lado de sua mesa durante a correção coletiva de um problema de matemática, em que era preciso subtrair 5 livros de 14 livros. Em 30 de março, é o dia de S. cuidar da organização da aula. Cada uma das tarefas que lhe são atribuídas torna-se uma oportunidade para uma atividade de linguagem. Antes de colocar uma folha na frente de cada um de seus colegas, ele disse "uma folha" (às vezes, acompanhado do nome do colega). Em outra distribuição, deixa a si mesmo por último e diz, em tom de brincadeira, algo que se aproxima de “quem é que não tem $\lambda$ ”. Depois, repete a mesma fala, aproximando-se da mesa da professora para colocar a última folha. Um pouco mais tarde, na mesma manhã, ele recolhe os cadernos e pronuncia, a cada vez, o nome da criança (o que não é usual). Quando chega nele mesmo, diz teatralmente "e eu”18.

O que é comum a estas intervenções linguísticas, além de serem uma oportunidade para S. explorar diferentes formas de ancoragem enunciativa se apoiando nas marcas de primeira pessoa, é sua natureza não-necessária, quase gratuíta e, portanto, não arriscada. Podemos considerar essas produções de linguagem como fala

\footnotetext{
${ }^{18}$ Ficamos tentados em aproximar estes enunciados do comentário que S. fez no mesmo dia enquanto começou um jogo de construção com Amal (que, no início, não era para ser um jogo competitivo). Uma primeira vez, ele declara "pronto" seguido rapidamente por "eu terminado" [Nota dos Trad. Em francês, ele diz ma fini, o que remeteria ao moi fini]. Depois, mostrando as duas construções: "você segundo, eu primeiro" [Nota dos Trad. Aqui, uma vez mais, ele diz ma premier]. Estes enunciados aproximam-se dos precedentes do ponto de vista dos micro-sistemas da interlíngua explorados, mesmo se se afastam destes mesmos enunciados pelo fato de que têm um destinatário evidente.
}

Olh@res, Guarulhos, v. 1, n. 2, p. 100-119, Novembro, 2013. 
egocêntrica, mesmo se elas não têm um destinatário evidente. Com efeito, o simples fato de que ocorrem em francês mostra que participam de uma prática de linguagem social. Certo, nada garante que essas práticas de linguagem permitirão uma aproximação da competência linguística de S. da dos falantes nativos, mas é difícil não ver nesta relação gratuíta, lúdica, à língua, e, ao mesmo tempo, muito focada em termos de micro-sistemas postos em prática, algo semelhante a uma estratégia de aprendizagem. Vê-se, portanto, que a análise dos vínculos entre estratégias de aprendizagem e estratégias de comunicação que apresentava o fato de se “assumirem riscos” como "uma condição necessária para que o locutor não-nativo se torne um candidato aprendente” (BANGE, 1992, p.67) deve ser minimizada.

\subsection{A exploração sistemática dos empregos de um item}

Em um contexto menos lúdico, com desafios comunicativos imediatos, mas de modo igualmente (se não mais) sistemático, S. explora os empregos possíveis da expressão “ou o quê” ( $c f$. recortes 3 e 4 infra, 08 e 09 de junho). Essas três ocorrências próximas de “ou o quê" nos mostra, de um lado, que ele identificou corretamente a expressão e que é capaz de reconstitui-la, de outro, que as condições de emprego dessa expressão não estão claramente fixadas, já que, apenas na intervenção 1 do recorte 3 , ela é de fato conforme a um emprego de um falante nativo.

Olh@res, Guarulhos, v. 1, n. 2, p. 100-119, Novembro, 2013. 


\section{Recorte 3: Preparação para “aula verde" - 08 de junho}

$<$ S tenta atrair a atenção de sua vizinha concentrada em um caderno. Ele a chama>

1. S.: Amal Amal Amal você não me entende $\pi \square$ Você não me entende ${ }^{19} \lambda$ Você não me entende ou o quể

$<$ Alguns minutos mais tarde: S. se voltou para uma colega sentada atrás dele. A professora fez a chamada e, quando chega em seu sobrenome, insiste nele.>

2. S.: Sim disse $\operatorname{sim}=$

3. P.: = Tudo bem, mas eu estou te chamando também para que + você se +

4. A.: vire

(...)

7. S.: Por quê

8. P.: Porque na sala, S. lembra para mim a regra

9. S.: trabalho ou o quê

10. P.: Nós trabalhamos, sim

\section{Recorte 4: Correções - 09 de junho}

Os alunos trabalham sozinhos, enquanto P. verifica os papéis para a aula verde.

S <para os colegas próximos ou para si mesmo > "eu, eu terminei ou o quê".

Poderíamos simplesmente concluir que há uma sobregeneralização do emprego de "ou o que”, ao qual S. parece atribuir uma função comunicativa bastante ampla, próxima daquela de "não é”. No entanto, S. usa três vezes a expressão em três horas de gravação feita nesses dois dias, misturando momentos em que efetivamente se arrisca (particularmente na intervenção 10 do recorte 2, em que os riscos não são apenas da ordem do malentendido) e a exploração mais mais próxima das formas de linguagem quase que auto-dirigidas evocadas em 2.2. Isto nos convida a concluir que há um “trabalho” sistemático de tipo estratégico.

\footnotetext{
${ }^{19} \mathrm{~A}$ entonação e o contexto permitem fazer a hipótese que ele quer lhe perguntar se ela o compreende.

Olh@res, Guarulhos, v. 1, n. 2, p. 100-119, Novembro, 2013.
} 


\section{Quando o papel de aluno e o papel de aprendiz de língua se} encontram: as identidades reconciliadas

Mostramos alguns aspectos das dificuldades que S. encontrava para assumir seu estatuto de aluno plurilíngue (negação de sua competência em albanês). Fizemos a hipótese de que esta recusa era devida provavelmente ao fato de que seu estatuto de aluno plurilíngue convocava, sem dúvida, a seus olhos de maneira imperiosa, uma outra dimensão de sua identidade que ele não queria ver tematizada nas interações, a saber, a de aluno não-francófono, de aluno aprendiz de francês, de aluno menos experiente em francês. Vimos também que essas negações não impediam S. de desenvolver sua competência linguística em francês e estudamos alguns dos lugares interacionais que parecem contribuir para suas aprendizagens linguísticas. Gostaríamos de terminar este estudo com um recorte da gravação coletada durante a nossa penúltima visita.

Neste dia, foi Bachir, figura importante do grupo de alunos de CE1, o responsável por ler o cardápio. Após oito interações para ajudar Bachir a ler a palavra "rilletes”20, K. intervém, interrompendo a professora:

\section{Extrato 5: Leitura do menu - 08 de junho de 2006 -}

1. K.: eu eu sei o que o que é "rillette"

2. S.: eu não, eu não ++ eu não

3. As + P.: <brouhaha $>$

4. P.: Ao mesmo tempo que Bachir fala, vocês escutam também einh?

5. S. Eu não $\lambda \mathrm{Eu}$

6. P.: você sabe o que é "rillettes" =

7. S.: = não

20 Nota dos Trad. Especialidade francesa que se assemelha a um patê com carne em pedaços, feito de carne de porco ou outros tipos de carne, misturadas ou não.

Olh@res, Guarulhos, v. 1, n. 2, p. 100-119, Novembro, 2013. 
A intervenção de K. em 1, que categoriza uma parte da sala - em todo caso, categoriza Bachir ${ }^{21}$ - como não sabendo o que são "rillettes", permite a S. de se categorizar, por sua vez, como não sabendo também o que é isso (eu não repetido três vezes). Certo, há uma ambiguidade nesta passagem sobre o que é desconhecido para os alunos (a palavra e/ou seu referente), mas é notável que S. aproveite desta ambiguidade para dizer, pela primeira vez em nosso corpus, que não conhece uma palavra. Saber dizer que não sabemos faz parte das competências do papel do aluno e é muito mais fácil “confessar” quando se vê que não se está sozinho. Neste contexto particular, que intervém no mês de junho, S., que adquiriu uma certa segurança linguística, parece encontrar um meio de conciliar a sua identidade de aluno da sala de CP-CE1 e sua identidade de aprendiz de língua.

Construir seu lugar nas interações de uma sala de alunos francófonos, quando se é o único aluno alófono, certamente não é uma tarefa fácil. A frequentação assídua em cursos específicos para alunos nãofrancófonos permite se categorizar legitimamente como "aprendiz de língua”, perceber seu avanço - graças, sobretudo, à chegada de outros alunos iniciantes em francês - e se envolver em intervenções de maior duração. Tudo isso se deve ao ambiente específico dessa classe, ao mesmo tempo mais "seguro" e mais aberto às conquistas metalinguísticas do que o de uma classe regular.

O estudo das interações em classes regulares revela, no entanto, múltiplas ocasiões para a criança alófona de conjugar aprendizagens escolares, socialização escolar e socialização linguística. A riqueza da articulação entre essas diferentes formas de engajamentos na interação delineada por este estudo convida a continuar a observação deste modo de integração escolar das crianças recém-chegadas.

\footnotetext{
${ }^{21}$ É possível que o fato de Bachir não comer carne de porco nas refeições contribua para a reação de K., que supõe, talvez, existir um vínculo entre esta prática alimentar e o desconhecimento desse alimento.

Olh@res, Guarulhos, v. 1, n. 2, p. 100-119, Novembro, 2013.
} 
O aluno com pouco domínio na língua da escolarização: convergência ou concorrência da socialização linguageira e da socialização escolar?

\section{Referências bibliográficas}

ARDITTY, Jo . Approches interactionnistes : exemples de fondements théoriques et questions de recherche, Le Français dans le Monde, Recherches et Application, Les interactions en classe de langue, 2005.

BANGE, Pierre. A propos de la communication et de l'apprentissage en L2, notamment dans ses formes institutionnelles, AILE 1, 53-58, 1992.

GAJO, Laurent et MONDADA, Lorenza. Interactions et acquisitions en contexte, Fribourg, Editions universitaires de Fribourg, 2000.

PALLOTTI, Gabriele. Variations situationnelles dans la construction des énoncés en L2 : le cas des autorépétitions, AILE 22, Interaction et diversité des conduites d'apprentissage, 2005.

RIVIERE, Véronique. Aujourd'hui nous allons travailler sur... , Le Français dans le Monde, Recherches et Application, Les interactions en classe de langue, 2005.

VASSEUR, Marie Therèse. En CLIN, l'apprentissage du français passe par la socialisation langagière, LINX, 49, Acquisition et communication en langue étrangère: Interlangue et communication exolingue / endolingue, Nanterre, 125-140, 2003.

VYGOTSKI, Lev S. Pensée et langage, La dispute, Paris, 1997.

WILLETT, Jerri. Becoming First Graders in an L2 : An Ethnographic Study of L2 socialization, TESOL Quarterly Vol. 29, 473-503, 1995.

\section{Tradutores}

Texto traduzido por Márcia Romero (Universidade Federal de São Paulo) e Thatiana Ribeiro Vilela (Universidade Federal de São Paulo).

Olh@res, Guarulhos, v. 1, n. 2, p. 100-119, Novembro, 2013. 